South African Journal of Geomatics, Vol. 7. No. 3, November 2018

\title{
A Method for Connecting Traverses to GNSS Controls Eliminating Troublesome Short GNSS Orientation Lines
}

\author{
Akajiaku C. Chukwuocha Ph.D. \\ Department of Surveying and Geoinformatics, Federal University of Technology, Owerri, \\ Nigeria, ac.chukwuocha@gmail.com, akajiaku.chukwuocha@futo.edu.ng
}

DOI: $\underline{\text { http://dx.doi.org/10.4314/sajg.v7i3.7 }}$

\begin{abstract}
Global Navigation Satellite System (GNSS) surveys are used to establish long baseline control networks. Further breaking down of the controls are accomplished using total station traversing connected to the GNSS networks. Auxiliary stations are established at relatively short distances to each GNSS main station for traverse azimuth orientation. If the GNSS azimuth reference lines are short, the allowable uncertainties in the GNSS determined coordinates heavily encumber the accuracies of the azimuths derived from them. This is the problem with connecting traverses to GNSS controls via azimuth reference lines that are short. Reorientation traversing can solve the short GNSS azimuth reference line problem by running control traverses linked to GNSS controls without referencing the short GNSS azimuth lines. Four reorientation traverses of total traverse lengths of $1.4 \mathrm{Km}$ to $5.1 \mathrm{Km}$ were run between GNSS network stations to demonstrate the validity of the new method. A corresponding traditional traverse was run to compare with each of the reorientation traverse cases. Some t-distribution tests established that there were no statistical differences between the coordinates determined by the reorientation traverses and the corresponding traditional traverses coordinates at the 99\% confidence level. $P$-value tests revealed that there were no significant probabilities of an extreme occurrence in which the coordinates from the two methods of traversing may be statistically different at the $P$ $<0.01$ confidence level. The research results thus show that reorientation traversing is a valid procedure that may be used to avoid the use of short GNSS reference lines.
\end{abstract}

Key Words: Global Navigation Satellite Systems (GNSS), Reorientation Traversing, Azimuth, Controls 


\section{Introduction}

Ground control densification has gained some interesting developments as a result of the evolution of high-tech digital ground surveying equipment in the recent decades. Generally the efforts to bring in control across great distances using traversing has given way to the use of GNSS for speed and accuracy. On the other hand traversing between GNSS control stations to fill in controls over shorter distances is conducted with the total stations for accuracy purposes (Hill, 2008).

The GNSS survey measurements result in point positions and thus the uncertainties in the measurements are positional factors of longitude and latitude, ellipsoidal height $(\lambda, \phi, h)$ or eastings and northings and elevation (E, N, el). Standards for GNSS surveys allow maximum uncertainties in horizontal positioning varying from $5 \mathrm{~mm}+5 \mathrm{ppm}$ to $10 \mathrm{~mm}+10 \mathrm{ppm}$ at $95 \%$ confidence level for the topmost class of control surveys depending on the use (Surveys Division, Arkansas Highway and Transportation Department (2013), Permanent Committee on Geodesy (PCG) (2014)). Over a distance of $3 \mathrm{~km}$ uncertainties of $20 \mathrm{~mm}$ and $40 \mathrm{~mm}$ respectively will be allowed by these provisions. The import is that the relative precision of the azimuth between two such GNSS positions improve as distances between the points increase since the effect of the uncertainty on the line vectors is inversely proportional with length. And thus the position uncertainties distort the line vectors more over shorter distances. On the other hand Total Stations directly measure line vectors of distances and directions and can achieve such good precisions in distances at between $1 \mathrm{~mm}+1 \mathrm{ppm}$ to $2 \mathrm{~mm}+2 \mathrm{ppm}$ and in directions at between 1" to 2" (Integrated Land Management Bureau 2009). These level of precision are not yet possible to be achieved from vectors derived from GNSS coordinates with best values at over shorter distances. For example Royal Institution of Chartered Surveyors (RICS) 2010 reports that the high-precision static GNSS used for the most sensitive analyses such as National/international networks and reference frame survey, geodetic surveys to establish transformation parameters, crustal/tectonic plate monitoring surveys yield point positions of $5 \mathrm{~mm}$ to $10 \mathrm{~mm}$, implying that uncertainties in the derived distances and directions will be of the magnitude of $10 \mathrm{~mm}$ to $20 \mathrm{~mm}$ and 21 " to 41 " respectively over a $100 \mathrm{~m}$ distance. The GNSS surveys thus provide higher accuracies over greater distances, while total station traversing which directly measure terrestrial vectors of distances and direction yield better accuracies over shorter distances.

The present practice requires that traverses be connected to GNSS control stations. To accomplish this auxiliary GNSS control reference stations are established near the main network stations to provide for azimuth reference from the GNSS control network to the traverse. If these 
reference lines are short they introduce unacceptable azimuthal uncertainties from the GNSS surveys into the traverse.

The important consideration of the magnitude of orientation error as a function of the length of an orientation reference mark from the GNSS control network station arises. Errors in azimuths derived from GNSS coordinates will be of larger magnitudes over shorter distances. Considering that if the coordinates at both ends of a line is in positional error of a maximum of $\pm 30 \mathrm{~mm}$ as shown in Figure 1, the azimuth derived from this $150 \mathrm{~m}$ length will be in error by 82.5 " while the error in the distance is $0.060 \mathrm{~m}$ and the linear accuracy of the determination of the distance will be $1 / 2,500$.

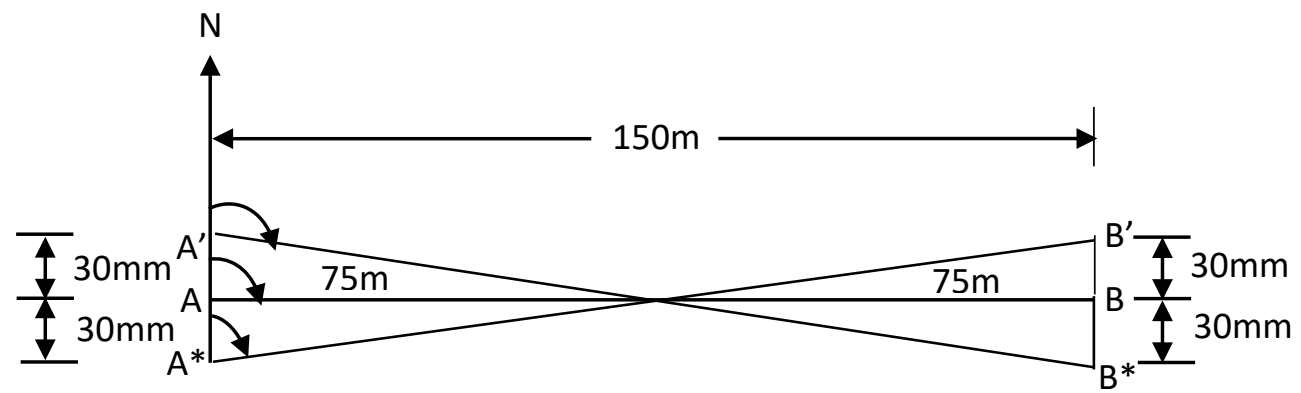

Figure 1. Illustration of the error in the traverse orientation due to GNSS station positional error

Ayers (2011) listed estimates of orientation errors in azimuths derived from Real Time Kinematic (RTK) GNSS survey relative to the length of the orientation line as in Table 1 considering the coordinates of the orientation mark to be in error by $\pm 20 \mathrm{~mm}$. Even though Table 1 lists a so called "orientation error best case scenario", practically the so called "orientation worst case scenario" is the valid case since these errors are uncertainties and no one can say which of the cases is applicable in any case.

Table 1: Estimates of Traverse Orientation Errors as a Function of the GNSS Reference Orientation line distance. Source: Ayers (2011)

\begin{tabular}{ccc}
\hline Distance & $\begin{array}{c}\text { Orientation Error Worst } \\
\text { Case Scenario }\end{array}$ & $\begin{array}{c}\text { Orientation Error Best Case } \\
\text { Scenario }\end{array}$ \\
\hline $10 \mathrm{~m}$ & $412^{\prime \prime}$ & $103 "$ \\
$30 \mathrm{~m}$ & $137 "$ & $35^{\prime \prime}$ \\
$100 \mathrm{~m}$ & $41^{\prime \prime}$ & $10^{\prime \prime}$ \\
$300 \mathrm{~m}$ & $14 "$ & $3 "$ \\
1000 & $4 "$ & $1 "$ \\
\hline
\end{tabular}

In practice so far, different survey establishments handle the issue of providing traverse controls from GNSS surveys differently. A sample of such surveys carried out by multinational 
and local companies in Nigeria show the varying approaches. In a technical Report GPS, SA (1989) on GNSS control survey of the XSV control station series in Nigeria, the orientation line distances sampled for control stations XSV-18, XSV-19, XSV-20, XSV-22 and XSV-23 ranged from $35 \mathrm{~m}$ to $49 \mathrm{~m}$. In another survey by the China National Petroleum Corporation for the Shell Petroleum Development Company, the distances of the orientation lines ranged from $75 \mathrm{~m}$ to 360m (China National Petroleum Corporation, 2007). Another GPS campaign technical report by TOPNAV for Chevron Nigeria Ltd reports that the orientation line distances ranged from $183 \mathrm{~m}$ to $413 \mathrm{~m}$ (TOPNAV, 1998).

United States Department of Agriculture - Forest Service and United States Department of the Interior - Bureau of Land Management (2001) instructs that station pairs used as azimuth or bearing reference for total station survey should be included in a network or measured with a minimum of two independent vectors using the RTK techniques in which the acceptable standard at the $95 \%$ confidence level of the local accuracy for cadastral project control application is less than $0.050 \mathrm{~m}$. Gardner (2013) provides that if GNSS is used to provide the reference line of a control traverse the line must be over $500 \mathrm{~m}$ in length.

The effort to use an appropriate length of orientation lines established by GNSS could suffer from quite some environmental constraints due to high rise buildings in urban areas or canopies in forested areas and so on. The aim of this research is to demonstrate a method that may be used to connect traverses to GNSS controls when appropriate lengths of GNSS control reference lines are not implementable in the circumstances.

The method of reorientation traversing is a resected traverse method that excludes setting up on the takeoff and/or closing control stations (Chukwuocha et al, 2017). The advantage of this method is that the reorientation traversing method will enable running of accurate traverses between reliable takeoff and closing single GNSS controls without encumbering the traverse with heavy loads of orientation error from short GNSS reference lines.

Reorientation traverses are run beginning with a setup of the angle measuring instrument on the first new station to be coordinated and a back sight taken to the takeoff GNSS control station to measure angle to the next traverse station. All the traverse distances are measured until the instrument is set up on the last traverse station to be coordinated with a fore sight to the closing GNSS control station. Indeed the reorientation traverse takes its orientation by indirect computations of the azimuth of the traverse from the line linking the two end GNSS controls using the geometry of the traverse figure as measured in the field.

Chukwuocha (2017) explains the computing of the reorientation traverse in two stages. In the first stage, an arbitrary azimuth is imposed on the first leg of the traverse and the traverse figure 
is computed beginning with the correct coordinates of takeoff control station giving arbitrary coordinates to all the traverse stations. Then the two angles at the control stations not observed in the field are computed from the coordinates of the ends of the appropriate lines. These derived angles are then used to compute the traverse in proper azimuth orientation using the coordinates of the end points of the control line.

\section{Materials and Methods}

Four different second order traverses were run with legs in the range of $450 \mathrm{~m}$ to demonstrate the feasibility of the reorientation traversing of connecting traverses of diverse total lengths to GNSS control stations. All the controls used in the traverses were established using dual frequency GNSS receivers in the fast static mode. Trimble Business Center ${ }^{\mathrm{TM}}$ GNSS software (Trimble Engineering and Construction Group 2011) was used to process the GNSS data in the fixed solution mode and all the coordinates were determined in the projected Nigeria (modified) Transverse Mercator map system after network adjustment. The results are presented in Table 2. The orthometric heights were determined on the OSU 91A geoid and by a determined constant for Owerri they are here produced with reference to the Lagos mean sea level datum.

Table 2. GNSS Controls for the Traverses

\begin{tabular}{ccccccc}
\hline Point ID & $\begin{array}{c}\text { Easting } \\
(\mathbf{m})\end{array}$ & $\begin{array}{c}\text { Easting } \\
\text { Error } \\
(\mathbf{m})\end{array}$ & $\begin{array}{c}\text { Northing } \\
\mathbf{( m )}\end{array}$ & $\begin{array}{c}\text { Northing } \\
\text { Error } \\
(\mathbf{m})\end{array}$ & $\begin{array}{c}\text { Elevation } \\
(\mathbf{m})\end{array}$ & $\begin{array}{c}\text { Elevation } \\
\text { Error } \\
(\mathbf{m})\end{array}$ \\
\hline GPS C1 & 503936.956 & 0.004 & 161089.006 & 0.004 & 69.280 & 0.011 \\
GPS C1A & 504917.646 & 0.004 & 161426.626 & 0.003 & 67.822 & 0.009 \\
GPS C4 & 504787.264 & 0.008 & 162189.820 & 0.009 & 69.383 & 0.035 \\
GPS C4A & 505067.433 & 0.005 & 161520.890 & 0.003 & 67.917 & 0.009 \\
GPS C6 & 504437.592 & 0.009 & 163067.269 & 0.008 & 69.029 & 0.024 \\
GPS C6A & 505332.343 & 0.009 & 163452.723 & 0.008 & 69.487 & 0.024 \\
GPS C9 & 505723.540 & 0.008 & 163605.980 & 0.007 & 71.769 & 0.022 \\
GPS C9A & 506398.844 & 0.014 & 163884.699 & 0.010 & 70.604 & 0.031 \\
GPS C12 & 505173.739 & 0.010 & 164903.402 & 0.008 & 69.738 & 0.024 \\
GPS C12A & 506259.136 & 0.012 & 165315.878 & 0.010 & 70.779 & 0.028 \\
\hline
\end{tabular}

The shortest traverse had two new stations and a traverse length of about $1.41 \mathrm{Km}$. The second traverse was of five new stations and had a total traverse length of about $2.8 \mathrm{Km}$. The third of seven new stations had a length of about $3.75 \mathrm{~km}$. Since it is becoming standard that traverses should not exceed 5Km (Survey Department Ministry of Development Brunei Darussalam, 2016), the longest traverse was designed to test the feasibility of the reorientation traversing at the longest traverse length and it had a total of ten new stations and was of a distance of $5.1 \mathrm{Km}$.

The traverse field observations were made using a 2" total station on two reflector targets. Apart from the general atmospheric correction factors set for the electronic distance meter (EDM) of the total station, 
distance measurement was set on refinement mode of average of 3 readings. Field observation of angles and distances were by the forced centering method. Angles were estimated by an average of a minimum of 5 zeroes on both faces. Grid distances on the Nigerian Transverse Mercator map projection system were determined from the mean of field measured distances. Table 3 presents the field observed quantities used in the computation of the traverses. The traverses were computed using the Bowditch traverse computation method and also by least squares adjustment using the adjust software.

The least squares adjustment were carried out using the ADJUST software provided with Ghilani (2010). The adjustment used parametric equations in which an observation equation was written for each distance, direction, or angle. Since these equations are all non-linear in the coordinates of the stations, they were linearized. The traverses in this research were closed by linking the traverses from one set of two control stations to another. In the link closed traverse cases there are n number of sides for ( $n-1)$ number of unknown stations each having two unknown coordinates in the system making $2(\mathrm{n}-1)$ unknowns. Where as in the same link closed traverses there are $n$ measured distances and $(n+1)$ number of angles. From the foregoing for these link closed traverses of $n$ sides, there were $r=(n+n+1)-2(n-$ 1) $=3$ redundant equations.

Table 3. Final Estimates of Field Observations of the Traverses

\begin{tabular}{|c|c|c|c|c|c|c|c|}
\hline \multicolumn{4}{|c|}{ First Traverse of 2 Unknown Stations } & \multicolumn{4}{|c|}{ Third Traverse of 7 Unknown Stations } \\
\hline $\mathrm{S} / \mathrm{N}$ & Stations & Traverse Angle & Grid Distance (m) & $\mathrm{S} / \mathrm{N}$ & Station & Traverse Angle & Grid Distance $(\mathrm{m})$ \\
\hline 1 & GPS C9 & $269^{\circ} 45^{\prime} 43.2^{\prime \prime}$ & 453.569 & 1 & GPS & $181^{\circ} 27^{\prime} 27.7^{\prime \prime}$ & 462.771 \\
\hline 2 & RT10 & $178^{\circ} 54^{\prime} 19.1^{\prime \prime}$ & 450.581 & 2 & RT5 & $179^{\circ} 05^{\prime} 47.7^{\prime \prime}$ & 481.810 \\
\hline 3 & RT11 & $181^{\circ} 14^{\prime} 15.0^{\prime \prime}$ & 505.006 & 3 & RT6 & $268^{\circ} 42^{\prime} 26.2^{\prime \prime}$ & 460.126 \\
\hline 4 & GPS C12 & $271^{\circ} 43^{\prime} 03.4^{\prime \prime}$ & & 4 & RT7 & $181^{\circ} 19^{\prime} 33.6^{\prime \prime}$ & 451.151 \\
\hline \multirow{2}{*}{\multicolumn{4}{|c|}{$\begin{array}{l}\text { R.T Takeoff Angle }(\text { Ref. GPS C9A })=269^{\circ} 45^{\prime} 39.0^{\prime \prime} \\
\text { R.T Closing Angle }\left(\text { Ref. GPS C12A) }=271^{\circ} 43^{\prime} 07.7^{\prime \prime}\right.\end{array}$}} & 5 & RT8 & $179^{\circ} 33^{\prime 2} 24.7^{\prime \prime}$ & 482.999 \\
\hline & & & & 6 & RT9 & $089^{\circ} 55^{\prime} 02.3^{\prime \prime}$ & 453.569 \\
\hline \multicolumn{4}{|c|}{ Second Traverse of 5 Unknown Stations } & 7 & RT10 & $178^{\circ} 54^{\prime} 19.1 "$ & 450.581 \\
\hline $\mathrm{S} / \mathrm{N}$ & Stations & Traverse Angle & Grid Distance $(\mathrm{m})$ & 8 & RT11 & $181^{\circ} 14^{\prime} 15.0^{\prime \prime}$ & 505.006 \\
\hline 1 & GPS C6 & $359^{\circ} 50^{\prime} 30.9^{\prime \prime}$ & 460.126 & 9 & GPS & $271^{\circ} 43^{\prime} 03.4$ & \\
\hline 2 & RT7 & $181^{\circ} 19^{\prime} 33.6^{\prime \prime}$ & 451.151 & & & & \\
\hline 3 & RT8 & $179^{\circ} 33^{\prime} 24.7^{\prime \prime}$ & 482.999 & \multirow{3}{*}{\multicolumn{4}{|c|}{ R.T Takeoff Angle (Ref. GPS C4A) = $181^{\circ} 27^{\prime} 23.4^{\prime \prime}$}} \\
\hline 4 & RT9 & $89^{\circ} 55^{\prime} 02.3^{\prime \prime}$ & 453.569 & & & & \\
\hline 5 & RT10 & $178^{\circ} 54^{\prime} 19.1^{\prime \prime}$ & 450.581 & & & & \\
\hline 6 & RT11 & $181^{\circ} 14^{\prime} 15.0^{\prime \prime}$ & 505.006 & \multirow{3}{*}{\multicolumn{4}{|c|}{ R.T Closing Angle (Ref. GPS C12A) $=271^{\circ} 43^{\prime} 07.7^{\prime \prime}$}} \\
\hline 7 & GPS C12 & $271^{\circ} 43^{\prime} 03.4^{\prime \prime}$ & & & & & \\
\hline \multicolumn{4}{|c|}{ R.T Takeoff Angle (Ref. GPS C6A) $=359^{\circ} 50^{\prime} 25.1^{\prime \prime}$} & & & & \\
\hline \multicolumn{8}{|c|}{\begin{tabular}{l|l} 
R.T. Closing Angle (Ref. GPS C12A) $=271^{\circ} 43^{\prime} 09.2^{\prime \prime}$ & \\
\end{tabular}} \\
\hline \multicolumn{8}{|c|}{$\begin{array}{c}\text { Fourth Traverse of } 10 \text { Unknown Stations } \\
\end{array}$} \\
\hline $\mathrm{S} / \mathrm{N}$ & Stations & Traverse Angle & Grid Distance $(\mathrm{m})$ & $\mathrm{S} / \mathrm{N}$ & Station & Traverse Angle & Grid Distance $(\mathrm{m})$ \\
\hline 1 & GPS C1 & $325^{\circ} 34^{\prime} 30.5^{\prime \prime}$ & 460.078 & 7 & RT7 & $181^{\circ} 19^{\prime} 33.6^{\prime \prime}$ & 451.151 \\
\hline 2 & RT2 & $180^{\circ} 19^{\prime} 13.6^{\prime \prime}$ & 452.614 & 8 & RT8 & $179^{\circ} 33^{\prime} 24.7^{\prime \prime}$ & 482.999 \\
\hline 3 & RT3 & $182^{\circ} 35^{\prime} 20.5^{\prime \prime}$ & 478.643 & 9 & RT9 & $89^{\circ} 55^{\prime} 02.3^{\prime \prime}$ & 453.569 \\
\hline 4 & RT4 & $119^{\circ} 14^{\prime} 39.5^{\prime \prime}$ & 462.771 & 10 & RT10 & $178^{\circ} 54^{\prime} 19.1 "$ & 450.581 \\
\hline 5 & RT5 & $179^{\circ} 05^{\prime} 47.7^{\prime \prime}$ & 481.810 & 11 & RT11 & $181^{\circ} 14^{\prime} 15.0^{\prime \prime}$ & 505.006 \\
\hline 6 & RT6 & $268^{\circ} 42^{\prime} 26.2^{\prime \prime}$ & 460.126 & 12 & GPS & $271^{\circ} 43^{\prime} 03.4^{\prime \prime}$ & \\
\hline \multicolumn{4}{|c|}{ R.T Takeoff Angle (Ref. GPS DC1A) $=325^{\circ} 34^{\prime} 28.7^{\prime \prime}$} & \multicolumn{4}{|c|}{ R.T Closing Angle (Ref. GPS DC12A) $=271^{\circ} 43^{\prime} 06.8^{\prime \prime}$} \\
\hline \multicolumn{8}{|c|}{ Note: R.T. = Reorientation Traversing } \\
\hline
\end{tabular}




\section{Results and Discussions}

The results of the linear accuracy estimation of each of the Bowditch computation of traverses are presented in Table 4. In all the cases the reorientation traversing resulted in better linear accuracies. Much is not to be made of the huge differences in the linear accuracies of some of the cases. The least squares adjustment provided more reliable comparisons of the results of the traverses.

Table 4. Results of the Traverse Cases Determined by Bowditch Adjustment

\begin{tabular}{cccccccc}
\hline U. St. & L $(\mathrm{m})$ & R.T. Accuracy & T.T. Accuracy & U. St. & L $(\mathrm{m})$ & R.T. Accuracy & T. T. Accuracy \\
\hline 2 & 1409.16 & $1 / 83,150$ & $1 / 76,830$ & 7 & 3748.01 & $1 / 257,510$ & $1 / 62,460$ \\
5 & 2803.43 & $1 / 219,510$ & $1 / 100,530$ & 10 & 5139.344 & $1 / 623,590$ & $1 / 44,230$ \\
\hline \multicolumn{7}{c}{ Note: R.T. - Reorientation Traverse; T.T. = Traditional Traverse; L = Total Traverse Length; } \\
U. St. = Number of Unknown Stations
\end{tabular}

Local accuracy values indicates the uncertainty of the position of a control point relative to the adjacent stations measured in the same system as an indicator of the level of reliability or quality of the control coordinates at the 95-percent confidence level. However an average value is reported for the set of control points adjusted in the same network. (Crown Registry and Geographic Base Branch, GeoBC (2009), Surveys Division, Arkansas Highway and Transportation Department (2013)).

Surveys Division, Arkansas Highway and Transportation Department (2013) provides a system for computation of the maximum allowable local accuracy of a traverse based on the class of the traverse and the total length. The maximum local accuracy for the highest accuracy type of control traverse, the Secondary Control (1-99) is $1 \mathrm{~cm}+10 \mathrm{ppm}$. For other lower accuracy controls it provides for a maximum local accuracy of $2 \mathrm{~cm}+50 \mathrm{ppm}$, while property survey traverses are allowed local accuracy of $2 \mathrm{~cm}+100 \mathrm{ppm}$. So for a second order control of $3 \mathrm{~km}$ length, the maximum local accuracy value allowed will be $2 \mathrm{~cm}+10(300,000 / 1,000,000) \mathrm{cm}=$ $2 \mathrm{~cm}+3 \mathrm{~cm}=5 \mathrm{~cm}$ or $50 \mathrm{~mm}$. Other Standards will include Crown Registry and Geographic Base Branch, GeoBC (2009) and Washington State Department of Transport (WSDOT) (2005).

The results of the traverses computed by the least squares adjustment together with their error statistics are presented in Table 5. The first traverse cases of total lengths of $1.4 \mathrm{Km}, 2.8 \mathrm{Km}$, $3.7 \mathrm{Km}$ and $5.1 \mathrm{Km}$ returned $11 \mathrm{~mm}, 11 \mathrm{~mm}, 22 \mathrm{~mm}$ and $33 \mathrm{~mm}$ respectively for the traditional traverses and $11 \mathrm{~mm}, 14 \mathrm{~mm}, 22 \mathrm{~mm}$ and $33 \mathrm{~mm}$ respectively for the reorientation traversing. All these were successful results since each case was lower than the maximum allowed by the standards of $34 \mathrm{~mm}, 48 \mathrm{~mm}, 57 \mathrm{~mm}$ and $71 \mathrm{~mm}$ respectively. It is thus demonstrated that the reorientation traversing method is suitable for linking the GNSS control stations with traverses of up to $5 \mathrm{Km}$ without the use of the short GNSS reference lines which would have encumbered the traverses. 
South African Journal of Geomatics, Vol. 7. No. 3, November 2018

Table 5: Adjusted Coordinates and Statistics Resulting from the 450m Legs Reorientation traverses and Traditional Traverses

\begin{tabular}{|c|c|c|c|c|c|c|c|c|c|c|c|c|}
\hline \multirow{2}{*}{$\begin{array}{l}\text { Number of } \\
\text { New } \\
\text { Stations }\end{array}$} & \multirow{2}{*}{ Station } & \multicolumn{5}{|c|}{ Reorientation Traverse } & \multicolumn{5}{|c|}{ Traditional Traverse } & \multirow{2}{*}{ Local Accuracy } \\
\hline & & $\mathrm{X}$ & $\mathrm{Y}$ & $\mathrm{Sx}$ & Sy & $r(95 \%)$ & $\mathrm{X}$ & $\mathrm{Y}$ & $\mathrm{Sx}$ & Sy & $\mathrm{r}(95 \%)$ & \\
\hline \multirow{2}{*}{$\begin{array}{c}2 \\
\Sigma \mathrm{D}=1.4 \mathrm{~km}\end{array}$} & PT10 & $505,548.751$ & $164,024.5231$ & \pm 0.0047 & \pm 0.0036 & 0.0104 & $505,548.752$ & $164,024.5241$ & \pm 0.0047 & \pm 0.0036 & 0.0104 & \multirow{2}{*}{$\begin{array}{l}\text { Reorient. } 0.0107 \\
\text { Trad. Trav: } 0.0107\end{array}$} \\
\hline & PT11 & $505,367.199$ & $164,436.915$ & \pm 0.0049 & \pm 0.0036 & 0.0109 & $505,367.199$ & $164,436.915$ & \pm 0.0049 & \pm 0.0036 & 0.0109 & \\
\hline \multirow{5}{*}{$\begin{array}{c}5 \\
\Sigma \mathrm{D}=2.8 \mathrm{~km}\end{array}$} & RT7 & $504,859.667$ & $163,250.491$ & \pm 0.0043 & \pm 0.0051 & 0.0117 & $504,859.668$ & $163,250.486$ & \pm 0.0032 & \pm 0.0038 & 0.0088 & \multirow{5}{*}{$\begin{array}{l}\text { Reorient.: } 0.0141 \\
\text { Trad. Trav. } 0.0106\end{array}$} \\
\hline & RT8 & $505,277.555$ & $163,420.513$ & \pm 0.0058 & \pm 0.0066 & 0.0153 & $505,277.556$ & $163,420.508$ & \pm 0.0044 & \pm 0.0049 & 0.0114 & \\
\hline & RT9 & $505,723.523$ & $163,605.991$ & \pm 0.0065 & \pm 0.0068 & 0.0162 & $505,723.522$ & $163,605.989$ & \pm 0.0049 & \pm 0.0051 & 0.0121 & \\
\hline & RT10 & $505,548.743$ & $164,024.532$ & \pm 0.0068 & \pm 0.0069 & 0.0153 & $505,548.739$ & $164,024.529$ & \pm 0.0051 & \pm 0.0042 & 0.0115 & \\
\hline & RT11 & $505,367.197$ & $164,436.921$ & \pm 0.0055 & \pm 0.0042 & 0.0122 & $505,367.193$ & $164,436.918$ & \pm 0.0041 & \pm 0.0031 & 0.0091 & \\
\hline \multirow{6}{*}{$\begin{array}{c}7 \\
\Sigma \mathrm{D}=3.7 \mathrm{~km}\end{array}$} & RT5 & $504,619.404$ & $162,621.075$ & \pm 0.0065 & \pm 0.0037 & 0.0139 & $504,619.407$ & $162,621.076$ & \pm 0.0065 & \pm 0.0037 & 0.0139 & \multirow{6}{*}{$\begin{array}{l}\text { Reorient: } 0.0220 \\
\text { Trad. Trav. } 0.0220\end{array}$} \\
\hline & RT6 & $504,437.580$ & $163,067.260$ & \pm 0.0119 & \pm 0.0062 & 0.0254 & $504,437.584$ & $163,067.262$ & \pm 0.0119 & \pm 0.0062 & 0.0254 & \\
\hline & RT7 & $504,859.656$ & $163,250.479$ & \pm 0.0133 & \pm 0.0061 & 0.0271 & $504,859.660$ & $163,250.479$ & \pm 0.0133 & \pm 0.0061 & 0.0271 & \\
\hline & RT8 & $505,277.544$ & $163,420.503$ & \pm 0.0134 & \pm 0.0065 & 0.0274 & $505,277.547$ & $163,420.503$ & \pm 0.0134 & \pm 0.0065 & 0.0274 & \\
\hline & RT9 & $505,723.510$ & $163,605.983$ & \pm 0.0124 & \pm 0.0069 & 0.0265 & $505,723.513$ & $163,605.985$ & \pm 0.0124 & \pm 0.0069 & 0.0265 & \\
\hline & RT11 & $505,367.191$ & $164,436.917$ & \pm 0.0062 & \pm 0.0036 & 0.0132 & $505,367.189$ & $164,436.917$ & \pm 0.0062 & \pm 0.0036 & 0.0132 & \\
\hline \multirow{10}{*}{$\begin{array}{c}10 \\
\Sigma \mathrm{D}=5.1 \mathrm{~km}\end{array}$} & RT2 & $504,211.126$ & $161,458.469$ & \pm 0.0051 & \pm 0.0044 & 0.0123 & $504,211.128$ & $161,458.468$ & \pm 0.0051 & \pm 0.0044 & 0.0123 & \multirow{4}{*}{ Reorient.: 0.0334} \\
\hline & RT3 & $504,482.881$ & $161,820.421$ & \pm 0.0100 & \pm 0.0082 & 0.0244 & $504,482.883$ & $161,820.419$ & \pm 0.0100 & \pm 0.0082 & 0.0244 & \\
\hline & RT4 & $504,787.263$ & $162,189.813$ & \pm 0.0147 & \pm 0.0123 & 0.0365 & $504,787.264$ & $162,189.812$ & \pm 0.0147 & \pm 0.0123 & 0.0365 & \\
\hline & RT5 & $504,619.413$ & $162,621.071$ & \pm 0.0188 & \pm 0.0119 & 0.0416 & $504,619.412$ & $162,621.069$ & \pm 0.0188 & \pm 0.0119 & 0.0416 & \\
\hline & RT6 & $504,437.581$ & $163,067.302$ & \pm 0.0201 & \pm 0.0237 & 0.0544 & $504,437.578$ & $163,067.296$ & \pm 0.0201 & \pm 0.0237 & 0.0544 & \multirow{6}{*}{ Trad. Trav: 0.0334} \\
\hline & RT7 & $504,859.662$ & $163,250.508$ & \pm 0.0200 & \pm 0.0174 & 0.0461 & $504,859.658$ & $163,250.503$ & \pm 0.0200 & \pm 0.0174 & 0.0461 & \\
\hline & RT8 & $505,277.554$ & $163,420.519$ & \pm 0.0191 & \pm 0.0108 & 0.0395 & $505,277.549$ & $163,420.516$ & \pm 0.0191 & \pm 0.0108 & 0.0395 & \\
\hline & RT9 & $505,723.523$ & $163,605.991$ & \pm 0.0173 & \pm 0.0087 & 0.0369 & $505,723.518$ & $163,605.989$ & \pm 0.0173 & \pm 0.0087 & 0.0369 & \\
\hline & RT10 & $505,548.744$ & $164,024.532$ & \pm 0.0125 & \pm 0.0066 & 0.0267 & $505,548.739$ & $164,024.53$ & \pm 0.0125 & \pm 0.0066 & 0.0267 & \\
\hline & RT11 & $505,367.197$ & $164,436.92$ & \pm 0.0072 & \pm 0.0041 & 0.0155 & $505,367.193$ & $164,436.919$ & \pm 0.0072 & \pm 0.0041 & 0.0155 & \\
\hline
\end{tabular}




\subsection{Statistical Tests of the Quality of Coordinates Determined by the Proposed Method}

The proposed method to connect control traverses to GNSS control stations without the short GNSS base lines has proved feasible since all the lengths met the required local accuracy standards. In furtherance tests were carried out to determine if there were any statistical differences between the coordinates as derived in the method of reorientation traversing and the corresponding coordinates derived by the traditional method. The statistical tests carried out in this research were comparison tests between the coordinates determined by the reorientation traversing process as the sample means, against the corresponding coordinates resulting from the already established method of traditional traversing as the population mean.

The t-distribution test is applied to testing if the sample mean is either statistically greater or less than the population mean. The t-distribution single-tail test is applied in such tests where the null hypothesis is set to find if the sample mean is statistically greater or less than the population mean. In the case being studied, the t-distribution two-tail test is applicable since the null hypothesis is set to find if the sample mean is within a prescribed confidence interval. The null hypothesis was whether the difference in the two means was equal to zero versus its alternative, of the difference not being equal to zero. The test statistic based on the difference in two means detailed by Ghilani (2010) for the t-distribution test was used. Since all the reorientation and traditional traverse cases contained the minimum number of observations, that is, $n_{1}=n_{2}$, the redundancies, $v_{1}=v_{2}=3$, the critical t0.005,6 value was 3.707 (Anglia Ruskin University, 2008) for all the traverses. The tests were carried out at the $99 \%$ confidence level.

The P-value test of the probability of observing a more extreme test statistic in the direction of the alternative hypothesis than the one observed. In the case of this present study the P-value tests were carried out to determine the probability of observing a more extreme test statistic of the coordinates derived from reorientation traversing differing from the traditional traversing. If the P-value is less than (or equal to) $\alpha$, then the null hypothesis is rejected in favour of the alternative hypothesis. And, if the P-value is greater than $\alpha$, then the null hypothesis is not rejected (Penn State Eberly College of Science, 2018). The p-value tests were carried out at the 99\% confidence level. Online calculator provided by Stangroom (2018) was used to calculate the P-values for the statistical tests.

Table 6 presents the results of the t-distribution and the P-value tests of the coordinates resulting from the traverses. The statistical tests results of the t-distribution indicates that the test failed to reject that the two means derived by the reorientation method and traditional method were different at a 0.01 level of confidence. The results show that not only does the reorientation traversing succeed in running a traverses that connect to single GNSS control stations at the 
required order of local accuracy it further shows that there is no statistical difference between the resulting coordinates of the traverses.

Table 7. 2-tail t-distribution and P-Value Tests of the Resulting Coordinates

\begin{tabular}{|c|c|c|c|c|c|c|c|c|c|c|}
\hline \multirow{2}{*}{ Traverse } & \multirow{2}{*}{ Station } & \multirow{2}{*}{$\begin{array}{c}\mathrm{n} 1= \\
\mathrm{n} 2\end{array}$} & \multirow{2}{*}{$\Delta \mathrm{X}$} & \multirow{2}{*}{$\Delta \mathrm{Y}$} & \multirow{2}{*}{$S_{x}^{2}$} & \multirow{2}{*}{$s_{y}^{2}$} & \multicolumn{2}{|c|}{$\begin{array}{c}\mathrm{t}-\text { Values } \\
\left(t_{0.005,6}=3.707\right)\end{array}$} & \multicolumn{2}{|c|}{$\begin{array}{l}\text { P-Values for } \\
\mathrm{P}<0.01\end{array}$} \\
\hline & & & & & & & $t$ for $X$ & $\begin{array}{c}\mathrm{t} \text { for } \\
\mathrm{Y}\end{array}$ & $\begin{array}{l}\text { P-value } \\
\text { of X }\end{array}$ & $\begin{array}{l}\text { P-value } \\
\text { for Y }\end{array}$ \\
\hline First & PT10 & 7 & 0.000 & 0.000 & 0.00002209 & 0.00001296 & 0.000 & 0.000 & 1.0000 & 1.0000 \\
\hline 2 Unknowns & PT11 & 7 & 0.000 & 0.000 & 0.00002401 & 0.00001296 & 0.000 & 0.000 & 1.0000 & 1.0000 \\
\hline \multirow{5}{*}{$\begin{array}{l}\text { Second } \\
5 \text { Unknowns }\end{array}$} & RT7 & 13 & -0.001 & 0.005 & 0.00001436 & 0.00002022 & -0.673 & 2.835 & 0.5492 & 0.0659 \\
\hline & RT8 & 13 & -0.001 & 0.005 & 0.00002650 & 0.00003378 & -0.495 & 2.193 & 0.6546 & 0.1159 \\
\hline & RT9 & 13 & 0.001 & 0.002 & 0.00003313 & 0.00003612 & 0.443 & 0.848 & 0.6878 & 0.4587 \\
\hline & RT10 & 13 & 0.004 & 0.003 & 0.00003612 & 0.00003262 & 1.697 & 1.339 & 0.1883 & 0.2730 \\
\hline & RT11 & 13 & 0.004 & 0.003 & 0.00002353 & 0.00001362 & 2.102 & 2.072 & 0.1263 & 0.1300 \\
\hline \multirow{7}{*}{$\begin{array}{l}\text { Third } \\
7 \text { Unknowns }\end{array}$} & RT5 & 17 & -0.003 & -0.001 & 0.00004225 & 0.00001369 & -1.346 & - & 0.2710 & 0.4882 \\
\hline & RT6 & 17 & -0.004 & -0.002 & 0.00014161 & 0.00003844 & -0.980 & - & 0.3994 & 0.4166 \\
\hline & RT7 & 17 & -0.004 & 0.000 & 0.00017689 & 0.00003721 & -0.877 & 0.000 & 0.4450 & 1.0000 \\
\hline & RT8 & 17 & -0.003 & 0.000 & 0.00017956 & 0.00004225 & -0.653 & 0.000 & 0.5603 & 1.0000 \\
\hline & RT9 & 17 & -0.003 & -0.002 & 0.00015376 & 0.00004761 & -0.705 & - & 0.5316 & 0.4602 \\
\hline & RT10 & 17 & 0.000 & 0.000 & 0.00009025 & 0.00002916 & 0.000 & 0.000 & 1.0000 & 1.0000 \\
\hline & RT11 & 17 & 0.002 & 0.000 & 0.00003844 & 0.00001296 & 0.940 & 0.000 & 0.4166 & 1.0000 \\
\hline \multirow{7}{*}{ Fourth } & RT2 & 23 & -0.002 & 0.001 & 0.00002601 & 0.00001936 & -1.330 & 0.771 & 0.2756 & 0.4969 \\
\hline & RT3 & 23 & -0.002 & 0.002 & 0.00010000 & 0.00006724 & -0.678 & 0.827 & 0.5464 & 0.4689 \\
\hline & RT4 & 23 & -0.001 & 0.001 & 0.00021609 & 0.00015129 & -0.231 & 0.276 & 0.8322 & 0.8005 \\
\hline & RT5 & 23 & 0.001 & 0.002 & 0.00035344 & 0.00014161 & 0.180 & 0.570 & 0.8686 & 0.6086 \\
\hline & RT6 & 23 & 0.003 & 0.006 & 0.00040401 & 0.00056169 & 0.506 & 0.859 & 0.6477 & 0.4535 \\
\hline & RT7 & 23 & 0.004 & 0.005 & 0.00040000 & 0.00030276 & 0.678 & 0.974 & 0.5464 & 0.4019 \\
\hline & RT8 & 23 & 0.005 & 0.003 & 0.00036481 & 0.00011664 & 0.888 & 0.942 & 0.4400 & 0.4157 \\
\hline \multirow{3}{*}{ С } & RT9 & 23 & 0.005 & 0.002 & 0.00029929 & 0.00007569 & 0.980 & 0.780 & 0.3994 & 0.4923 \\
\hline & RT10 & 23 & 0.005 & 0.002 & 0.00015625 & 0.00004356 & 1.356 & 1.028 & 0.2681 & 0.3796 \\
\hline & RT11 & 23 & 0.004 & 0.001 & 0.00005184 & 0.00001681 & 1.884 & 0.827 & 0.1561 & 0.4689 \\
\hline
\end{tabular}

\section{Conclusion and Recommendations}

This research has demonstrated the feasibility of the reorientation traversing method to connect control traverses beginning at single GNSS control stations and ending at single GNSS control stations devoid of short GNSS reference lines. The reorientation traversing method thus reduces the need for the problematic short azimuth orientation reference lines. Thus it provides a seamless interface between GNSS established control networks and the densification of controls using the optical methods of horizontal control establishment.

The t-distribution test revealed that for all the cases of the traverses of up to $5 \mathrm{Km}$, which standards provide for as the longest distances that traverses should be run, there is statistically no difference between the coordinates resulting from the reorientation traversing and the traditional traversing at the $99 \%$ confidence level. The P-value test proved that there is no significant probability of observing a significant difference between the coordinates resulting from reorientation traversing and the traditional traversing. 
It is recommended that Surveyors should pay more attention to the implication of short GNSS azimuth reference lines in traversing. The use of the method of the reorientation traversing for control extension from GNSS controls where appropriate reference line distances are not possible is strongly recommended since this research has shown that the same quality of results will be derived by the new method as with the traditional traversing method.

Additionally, the method of reorientation traversing recommends itself in cases where the control stations are orphaned either by obstructions that eliminate intervisibility between the main control stations and the auxiliary reference stations or by uprooted of auxiliary stations. The method is also applicable when forest canopies or urban facilities inhibit planting of the controls at appropriate distances.

\section{Acknowledgements}

I would like thank the team that took these field measurements and reduction of the data including Mr. Franklin Onyeagoro, Mr. Uzonnaya Ihenacho, Mr. Chima Diala and Mr. Wisdom Okerafor.

\section{References}

Anglia Ruskin University. 2008. 'Numbers Toolkit:t-test' Viewed 2nd January, 2018 web.anglia.ac.uk/numbers/biostatistics/t_test/local_folder/critical_values.html

Ayers HB, 2011. GNSS (GPS and GLONASS) Positioning used in Land Surveying and Engineering, Presented at the Joint Association of Manitoba Land Surveyors (AMLS)/ Association of Professional Engineers and Geoscientists of the Province of Manitoba (APEGM) Professional Development Seminar on GPS Best Practices Workshop Winnipeg, Manitoba, Canada. ,http://www.apegm.mb.ca/pdf/PD_Papers/GNSSPositioning.pdf

China National Petroleum Corporation, 2007. Technical Report on the Global Positioning System Survey in Oil Mining License 53 of Nigeria. Chevron Nigeria Ltd.

Crown Registry and Geographic Base Branch, GeoBC, 2009. British Columbia Specification and Guidelines for Control Surveys Using Conventional Survey Technology. Integrated Land Management Bureau pp. $18-19$.

Chukwuocha, AC., Moka, EC., Uzodimma, VN, Onoh, MN. 2017. 'Solving Control Reference Azimuth Problems of Traversing Using Reorientation Traversing'. Surveying and Land Information Science Journal, Vol 76 (1). pp. 23 - 37. Viewed $5^{\text {th }}$ July 2017

http://www.ingentaconnect.com/content/aags/salis/2017/00000076/00000001/art00004

Chukwuocha, A. C. 2017. 'Case Studies of Reorientation Traversing.' Surveying and Land Information Science November, 2017 Vol. 76 (2). pp. 107-117. Viewed $12^{\text {th }}$ February 2018

http://www.ingentaconnect.com/content/aags/salis/2017/00000076/00000002/art00005?crawler=true Gardner, L., 2013. 'Surveyor General's Directions No 9: Global Navigation Satellite System for Cadastral Surveys. ' Surveyor General of New South Wales. Viewed March 16, 2017 
http://spatialservices.finance.nsw.gov.au/ data/assets/pdf file/0006/25944/sgddir9 Ver2.5 May 2014.pdf Hill, C., 2008.' Integration of GPS and Total Station Technologies'. Surveying Technical pp. 28 -32. Viewed $20^{\text {th }}$ March 2017, http://www.ee.co.za/wp-content/uploads/legacy/SurvT\%20-\%20Integration\%20of\%20GPS2.pdf.

Ghilani, C. D. 2010. Adjustment Computations - Spatial data Analysis $5^{\text {th }}$ Ed. New Jersey, John Wiley and Sons pp. $68-80$.

-. 2010. Adjustment Computations - Spatial data Analysis $5^{\text {th }}$ Ed. New Jersey, John Wiley and Sons pp. $298-326$.

GPS SA, 1989. Technical Report on GNSS Control Survey of the XSV Control Station Series. Nigeria National Petroleum Corporation.

Penn State Eberly College of Science 2018. Statistics Online. The Pennsylvania State University Viewed March 1, 2018. https://onlinecourses.science.psu.edu/statprogram/node/138

Permanent Committee on Geodesy (PCG) 2014. Guideline for Control Surveys by GNSS Special Publication 1. Intergovernmental Committee on Surveying and Mapping (ICSM), Commonwealth of Australia. Viewed March 1, 2018. https://www.icsm.gov.au/sites/default/files/2018-02/Guideline-forControl-Surveys-by-GNSS_v2.1.pdf

Royal Institution of Chartered Surveyors (RICS) 2010. Guidelines for the use of GNSS in land surveying and mapping 2nd ed. Royal Institution of Chartered Surveyors (RICS) Coventry, UK http://www.rics.org/Global/Downloads/Guidelines_for_the use_of_GNSS in_surveying_and mappin g_2nd_edition_PGguidance_2010.pdf

Stangroom, J. (2018). Social Science Statistics. Viewed $1^{\text {st }}$ March 2018

http://www.socscistatistics.com/pvalues/tdistribution.aspx

Surveys Division Arkansas Highway and Transportation Department. 2013. "Requirements and Procedures for Control, Design, and Land Surveys." Viewed 26 $6^{\text {th }}$ August 2015 http://www.ahtd.ar.gov/surveys_division/manuals/Surveys.pdf

TOPNAV, 1998. A Technical Report on the Global Position System Control Network Campaign of Oil Mining License 053 Owerri Nigeria. Chevron Nigeria Ltd Lagos.

Trimble Engineering and Construction Group 2011. Trimble Business center 2.50 Software. Dayton, Ohio, U.S.A.

United States Department of Agriculture - Forest Service and United States Department of the Interior Bureau of Land Management 2001. 'Standards and Guidelines for Cadastral Surveys Using Global Positioning System $\quad$ Methods'. Viewed $24^{\text {th }} \quad$ March 2017. https://www.blm.gov/or/gis/geoscience/files/CadGPSstd.pdf

Washington State Department of Transport WSDOT 2005. Highway Surveying Manual. pp.7-1 -7-10 Viewed 1st March 2018. https://www.wsdot.wa.gov/publications/ 